\title{
Acute effects of transcutaneous electrical diaphragmatic stimulation on respiratory pattern in COPD patients: cross-sectional and comparative clinical trial
}

\author{
Karina M. Cancelliero-Gaiad ${ }^{1}$, Daniela Ike ${ }^{1}$, Camila B. F. Pantoni ${ }^{2}$, \\ Renata G. Mendes ${ }^{2}$, Audrey Borghi-Silva ${ }^{2}$, Dirceu Costa ${ }^{1,3}$
}

\begin{abstract}
Background: Transcutaneous electrical diaphragmatic stimulation (TEDS) has been used to improve respiratory muscle strength in patients with respiratory muscle weakness. However, this physical therapy resource has not been studied in chronic obstructive pulmonary disease (COPD). Objective: To evaluate the respiratory pattern during one session of TEDS in COPD patients. Method: Fifteen COPD patients participated in one TEDS session for plethysmographic analysis and assessment of peripheral oxygen saturation $\left(\mathrm{SpO}_{2}\right)$ and heart rate (HR). After the session, patients were divided into two groups: Responder (R; $n=9)$ and Non-Responder (NR; $n=6)$ to TEDS. Statistic analysis was performed using the Shapiro-Wilk normality test and two-way ANOVA. For the parameters that showed interaction, the Student $t$ test was used $(\mathrm{P}<0.05)$. Results: $\mathrm{R}$ group consisted mainly of men, with lower $\mathrm{SpO}_{2}$ and higher HR than NR group. When time (before and during) and groups (R and NR) were compared (interaction), there were differences in the parameters minute ventilation (Vent), inspiratory tidal volume (ViVol), expiratory tidal volume (VeVol), and respiratory rate $(\mathrm{Br} / \mathrm{M})$. In the intergroup comparison, differences were observed in the parameters Vent, ViVol, and VeVol. A significant effect was also observed for time in change in end-expiratory lung volume level (qDEEL), phase relation during inspiration (PhRIB); phase relation during expiration (PhREB); phase relation of entire breath (PhRTB), and phase angle (PhAng). During TEDS, there was an increase in $\mathrm{SpO}_{2}$ and a reduction in HR in both groups Conclusions: The most hypoxemic group with greater HR responded to TEDS and there was interaction between group and time of analysis for the pulmonary volumes. The time factor had an influence on the two groups with an increase in thoracoabdominal asynchrony.
\end{abstract}

Keywords: chronic obstructive pulmonary disease; diaphragm; electrical stimulation; pulmonary rehabilitation. Clinical Trial Registration number: NCT01300442.

\section{HOW TO CITE THIS ARTICLE}

Cancelliero-Gaiad KM, Ike D, Pantoni CBF, Mendes RG, Borghi-Silva A, Costa D. Acute effects of transcutaneous electrical diaphragmatic stimulation on respiratory pattern in copd patients: cross-sectional and comparative clinical trial. Braz J Phys Ther. 2013 Nov-Dec; 17(6):547-555. http://dx.doi.org/10.1590/S1413-35552012005000121

\section{Introduction}

According to Weiner and $\mathrm{McConell}^{1}$, respiratory muscle dysfunction is a common consequence of chronic obstructive pulmonary disease (COPD). McKenzie et al. $^{2}$ reported that the function of inspiratory muscles is compromised in COPD due to increased loads, reduced mechanical advantage, and increased ventilatory requirements. Moreover, when hyperinflation is presented in COPD, it reduces the flow and pressure-generating capacity of the diaphragm, which is compensated by neural drive, adaptations of the chest wall and diaphragm shape to accommodate the increased volume, and adaptations of muscle fibers to preserve strength and increase endurance. In addition to muscle weakness, COPD patients present abnormalities in breathing pattern and thoracoabdominal motion that may contribute to exercise limitation ${ }^{3}$.

Pulmonary rehabilitation (PR) programs have been defined as an "evidence-based, multidisciplinary, and comprehensive intervention for patients with chronic respiratory disease, who are symptomatic and often have decreased daily life activities"4. In COPD patients, PR has also been shown to increase exercise endurance, decrease dyspnea, improve

\footnotetext{
${ }^{1}$ Respiratory Physical Therapy Laboratory, Postgraduate Program in Physical Therapy, Universidade Federal de São Carlos (UFSCar),

${ }^{2}$ Cardiopulmonary Physical Therapy Laboratory, Nucleus of Research in Physical Exercise, UFSCar, São Carlos, SP, Brazil

${ }^{3}$ Respiratory Functional Laboratory, Postgraduate Program in Rehabilitation Science, Universidade Nove de Julho (UNINOVE),

São Paulo, SP, Brazil

Received: 10/09/2012 Revised: 04/23/2013 Accepted: 06/03/2013
} 
health-related quality of life, and reduce healthcare $\operatorname{costs}^{4,5}$. However, in patients with more severe COPD, the benefits of rehabilitation may be limited. In this context, there are new approaches to PR, such as electrical stimulation, a technique that externally stimulates contractions of peripheral muscles to improve peripheral muscle function in patients with severe $\mathrm{COPD}^{6}$.

In the past, transcutaneous electrical diaphragmatic stimulation (TEDS) demonstrated positive effects in patients with weakness and respiratory muscle dysfunction ${ }^{7-9}$. However, there have been no studies on the application of TEDS in COPD patients, which underlines the need for elucidation of respiratory pattern behavior under these circumstances, before the technique is implemented in a rehabilitation program.

Thus, the aim of the present study was to investigate the respiratory pattern of COPD patients during one TEDS session. The hypothesis of the present study was that there would be marked differences in respiratory pattern during the TEDS session related to thoracoabdominal coordination and pulmonary volumes, without change in time measures, since these measures are standardized in the electrical current.

\section{Method}

\section{Design}

The study was a cross-sectional, comparative, and non-randomized clinical trial. The intervention with TEDS was applied in a single session in which the respiratory pattern was evaluated by respiratory inductance plethysmography (RIP). Saturation of peripheral oxygen $\left(\mathrm{SpO}_{2}\right)$ and heart rate $(\mathrm{HR})$ were also assessed. The study protocol was approved by the Research Ethics Committee of Universidade Federal de São Carlos (UFSCar), São Carlos, SP (Protocol 073/2009), and all participants signed an informed consent form to take part in the research.

\section{Participants}

A total of 30 subjects with stable COPD (diagnosed by accepted criteria) ${ }^{10}$ of both sexes were screened, of which 15 subjects were selected for inclusion in the study (Figure 1). For all COPD subjects, the exclusion criteria were as follows: age over 80 years; history of recent exacerbation; and patients with pacemakers, uncontrolled arterial hypertension or need for home oxygen therapy. The selected subjects had a documented medical history of COPD; were receiving medical therapy with pulmonary drugs; and

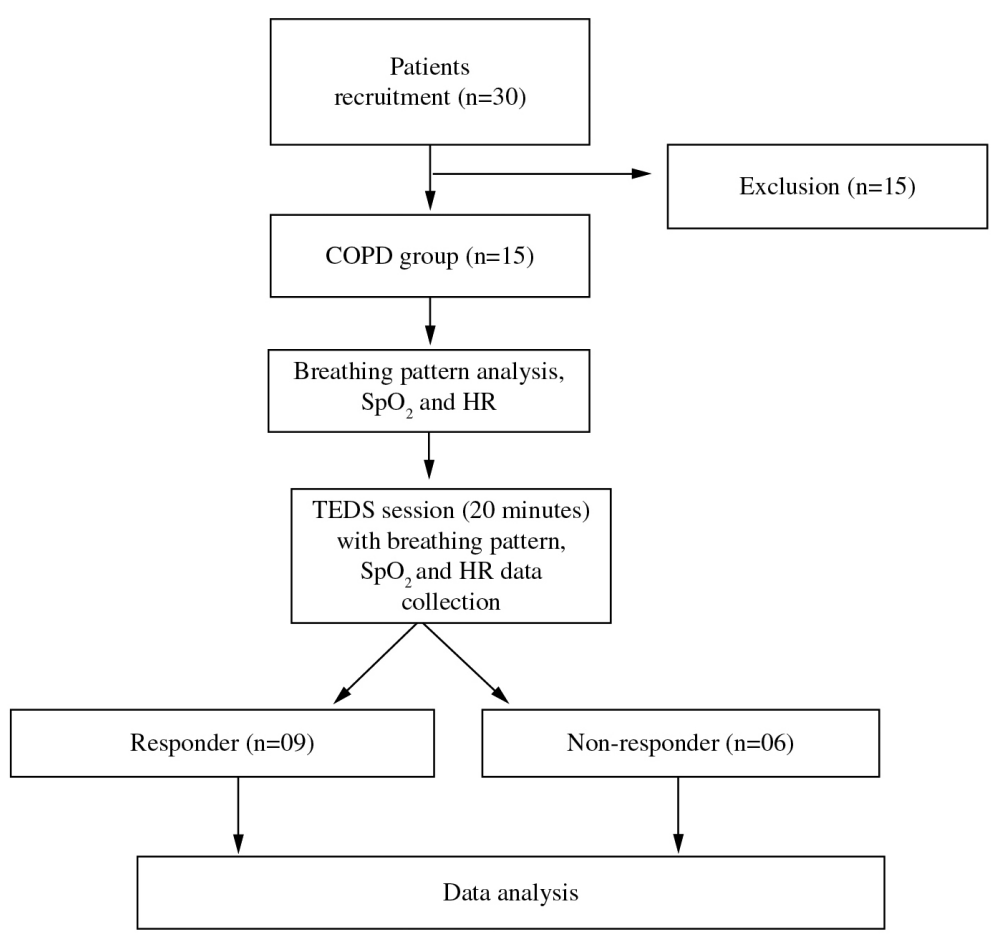

Figure 1. Experimental protocol. 
all of them were smokers or former smokers. None of them had any clinical or physiological features of bronchial asthma.

\section{Instruments}

For the TEDS procedure, the Dualpex 961 model Phrenics (Quark ${ }^{\circledR}$; Piracicaba, São Paulo, Brazil) equipment was used. The electrical current was pulsed, biphasic, and symmetric, with the following parameters: frequency of 30 hertz (cycle per second); phase width (pulse duration) of $0.4 \mathrm{~ms}$; rise time of 0.7 seconds; and respiratory rate of $15 \mathrm{rpm}^{11}$. The intensity of the current was the minimum necessary to obtain diaphragm muscle contraction and give the subjects a pleasant sensation ${ }^{12}$.

\section{Intervention}

Data collection was performed before (10 minutes) and during (20 minutes) the TEDS intervention. For this purpose, 4 silicone-carbon electrodes $(3 \times 5 \mathrm{~cm})$ were placed on the clean skin with gel and micropore tape $\left(3 \mathrm{M}^{\circledR}\right)$. Two electrodes were located on each side of the thorax, specifically on the $3^{\text {rd }}$ intercostal space near the xiphoid region and on the $7^{\text {th }}$ intercostal space, on the mid-axillary line. Each session lasted 20 minutes, and the subjects were instructed to coordinate their breathing with the pulsing of the electrical current. The subjects remained in the semiFowler position $\left(30^{\circ}\right)$ with the lower extremities extended and arms alongside the body.

The breathing pattern was recorded by means of the respiratory inductive plethysmography (RIP) LifeShirt ${ }^{\circledR}$ System (VivoMetrics; Ventura, CA, USA), which was previously calibrated ${ }^{13}$. This device is based on the self-inductance of two coils placed around the rib cage and abdomen by means of two elastic straps, and it enables noninvasive measurements of BP. A specific $800 \mathrm{ml}$ bag was used for the volumetric adjustment procedure with RIP ${ }^{14}$.

\section{Outcome measures}

For breathing pattern analysis, the following variables were used:

- Volume measures: inspiratory tidal volume (ViVol); expiratory tidal volume ( $\mathrm{VeVol})$; minute ventilation (Vent); change in end-expiratory lung volume level (qDEEL);

- Time measures: respiratory rate (Br/M); inspiratory time (Ti); expiratory time (Te); total breath time $(\mathrm{Tt})$;
- Thoracoabdominal coordination measures: phase relation during inspiration (PhRIB); phase relation during expiration (PhREB); phase relation of entire breath (PhRTB); phase angle (PhAng), and percent rib cage inspiratory contribution to tidal volume ratio (\%RCi);

- Derivative measures: peak inspiratory flow (PifVt); peak inspiratory flow of rib cage (PifRC); peak inspiratory flow of abdomen (PifAB);

- Acceleration measures: peak inspiratory acceleration $(\mathrm{PiaVt})$; peak inspiratory acceleration of rib cage (PiaRC); peak inspiratory acceleration of abdomen (PiaAB).

To obtain the RIP sum signal for absolute volume in $\mathrm{mL}$, a quantitative calibration was carried out (fixed volume least squares calibration) before analysis of the respiratory variables. The data were downloaded from the RIP recorder to a computer and were analyzed by specific software (VivoLogic; VivoMetrics), which provided a breath-by-breath calculation of the breathing pattern variables. In addition to this, the $\mathrm{SpO}_{2}$ and $\mathrm{HR}$ were collected before and during intervention, 5 minutes before TEDS application, and in the $10^{\text {th }}$ minute of the TEDS phase.

\section{Data analysis}

Normal distribution of the data was evaluated using the Shapiro-Wilk normality test. After this, two-way ANOVA was applied. For the parameters that showed interaction between the groups (Responder and NonResponder) and times of analysis (before and during TEDS), the Student $t$ test was applied between the values (delta values: Time 2 [during TEDS] - Time 1 [before]). Fischer's test was used for the variables, such as number of individuals of each sex and actual condition related to smoking.

A $\mathrm{P}<0.05$ value was considered statistically significant. The SPSS 10.0 software package (Chicago, IL, USA) was used. The calculation of sample power was made by GraphPad StatMate ${ }^{\circledR}$ 2.00 , and the founded value was $99 \%$ in the COPD group $(n=15)$ by the Vent measure.

\section{Results}

Table 1 shows the anthropometric and spirometric characteristics of the 15 individuals with COPD, including the maximal respiratory pressures with the predicted values by Costa et al. ${ }^{15}$. 
Table 2 shows the plethysmography variables of the respiratory pattern before and during TEDS. The variables show that TEDS did not alter the ventilatory parameters. However, when the individual results were examined, a highly heterogeneous response was shown: 9 responders to the TEDS intervention, that is, with increase in Vent and 6 non-responders, that is, with decrease in Vent.

With relation to derivative and acceleration measures, there were differences during the TEDS session represented by an increase of $20.6 \%$ in PifAB and of $20.8 \%$ in PiaAB as shown in the table 2. The PiaVt also showed a difference represented by an increase of $33.31 \%$.

After dividing the sample into groups, classified as Responders ( $\mathrm{R} ; \mathrm{n}=9$ ) or Non-Responders (NR; $n=6$ ), some differences were observed between the groups, such as in gender, height, and $\mathrm{SpO}_{2}$ and $\mathrm{HR}$ variables $(\mathrm{P}<0.05)$, with high values for the female gender and $\mathrm{SpO}_{2}$, and low height and $\mathrm{HR}$ values in the NR group, as shown in Table 3.

Two-way ANOVA was applied to evaluate the effect of time (before and during TEDS) and of groups ( $\mathrm{R}$ and $\mathrm{NR}$ ) on the plethysmography data

Table 1. Anthropometric and spirometric variables of the COPD Group $(n=15)$.

\begin{tabular}{|c|c|}
\hline Variable & $\operatorname{COPD}(n=15)$ \\
\hline Age (years) & $65.3 \pm 7.3$ \\
\hline Gender female & 7 \\
\hline Current smoker & 8 \\
\hline \multicolumn{2}{|l|}{ COPD } \\
\hline Very Severe/Severe/Mild & $1 / 8 / 6$ \\
\hline Height (m) & $1.6 \pm 0.1$ \\
\hline Weight (kg) & $66.3 \pm 10.9$ \\
\hline BMI $\left(\mathrm{kg} / \mathrm{m}^{2}\right)$ & $24.6 \pm 4.8$ \\
\hline FVC (\% predicted) & $70.2 \pm 16.2$ \\
\hline $\mathrm{FEV}_{1}(\%$ predicted $)$ & $46.9 \pm 11.1$ \\
\hline $\mathrm{FEV}_{1} / \mathrm{FVC}(\%$ predicted $)$ & $65.0 \pm 8.9$ \\
\hline $\mathrm{HR}(\mathrm{bpm})$ & $81.7 \pm 13.9$ \\
\hline $\mathrm{SpO}_{2}(\%)$ & $95.8 \pm 3.0$ \\
\hline $\mathrm{MIP}\left(\mathrm{cmH}_{2} \mathrm{O}\right)$ & $-64.7 \pm 27.2$ \\
\hline MIP predicted ${ }^{\#}\left(\mathrm{cmH}_{2} \mathrm{O}\right)$ & $-59.8 \pm 15.3$ \\
\hline $\mathrm{MEP}\left(\mathrm{cmH}_{2} \mathrm{O}\right)$ & $81.4 \pm 28.6$ \\
\hline MEP predicted ${ }^{\#}\left(\mathrm{cmH}_{2} \mathrm{O}\right)$ & $88.2 \pm 13.3$ \\
\hline
\end{tabular}

Data are reported as mean $\pm \mathrm{SD}$. $\mathrm{BMI}=$ body mass index; $\mathrm{SpO}_{2}=$ peripheral oxygen saturation; $\mathrm{FVC}=$ forced vital capacity; $\mathrm{FEV}_{1}=$ forced expiratory volume in first second; HR: heart rate; MIP= maximal inspiratory pressure; $\mathrm{MEP}=$ maximal expiratory pressure. \# predicted by Costa et al. ${ }^{15}$.
(Table 4), with differences being observed for the parameters Vent, ViVol, VeVol, Br/M, PifVt, and $\% \mathrm{RCi}$ in the time vs. group interaction. Therefore, the results describe the simultaneous influence of the times analyzed (before and during the TEDS) and of the groups in the results. A significant effect of time was also observed for the parameters qDEEL, PhRIB, PhREB, PhRTB, and PhAng, as shown in Table 4.

After this analysis, the $t$ test was applied for the delta values (during the TEDS - before) of the R and NR groups for the parameters that showed interaction. With regard to the delta values, these were higher in $\mathrm{R}$ than in NR for the following four parameters: Vent (R: $1.89 \pm 2.32$; NR: $-2.12 \pm 0.70 ; \mathrm{L} / \mathrm{min}), \mathrm{ViVol}(\mathrm{R}$ : 125.15 \pm 124.07 ; NR: $-74.34 \pm 31.67$; $\mathrm{mL}), \mathrm{VeVol}(\mathrm{R}$ : 118.62 $\pm 136.70 ; \mathrm{NR}:-61.11 \pm 54.87 ; \mathrm{mL})$, and $\mathrm{Br} / \mathrm{M}$ (R: $0.81 \pm 3.60 ; \mathrm{NR}:-1.38 \pm 2.64 ; \mathrm{rpm}$ ) showing that

Table 2. Plethysmography data of the COPD group $(n=15)$.

\begin{tabular}{cccc}
\hline Variable & Before & During TEDS & P \\
Vent (L/min) & $7.6 \pm 3.6$ & $7.9 \pm 3.5$ & 0.69 \\
ViVol (mL) & $414.7 \pm 127.3$ & $460.0 \pm 191.6$ & 0.23 \\
VeVol (mL) & $413.7 \pm 117.0$ & $460.4 \pm 190.7$ & 0.22 \\
qDEEL & $85.6 \pm 40.3$ & $141.1 \pm 55.5$ & 0.004 \\
Ti (s) & $1.4 \pm 0.5$ & $1.3 \pm 0.2$ & 0.46 \\
Te (s) & $2.6 \pm 0.8$ & $2.6 \pm 0.4$ & 0.84 \\
Tt (s) & $3.9 \pm 1.1$ & $3.9 \pm 0.4$ & 0.99 \\
Br/M (rpm) & $17.2 \pm 3.5$ & $17.1 \pm 1.7$ & 0.94 \\
PhRIB (\%) & $12.1 \pm 4.9$ & $19.7 \pm 8.2$ & 0.001 \\
PhREB (\%) & $8.9 \pm 3.7$ & $17.8 \pm 6.1$ & 0.0005 \\
PhRTB (\%) & $10.6 \pm 4.6$ & $18.4 \pm 7.3$ & 0.0006 \\
PhAng $(\%)$ & $14.4 \pm 7.4$ & $26.4 \pm 10.1$ & $<0.0001$ \\
PifVt & $604.3 \pm 297.2$ & $680.0 \pm 358.9$ & 0.26 \\
Pif RC & $364.5 \pm 190.1$ & $389.9 \pm 143.9$ & 0.61 \\
PifAB & $303.4 \pm 182.0$ & $365.8 \pm 210.8$ & 0.02 \\
PiaVt & $1331.6 \pm 401.7$ & $1775.2 \pm 668.87$ & 0.01 \\
PiaRC & $959.4 \pm 351.9$ & $1174.9 \pm 431.7$ & 0.10 \\
PiaAB & $709.8 \pm 407.1$ & $857.1 \pm 436.9$ & 0.02 \\
\%RCi & $60.4 \pm 25.1$ & $65.9 \pm 24.4$ & 0.09 \\
\hline
\end{tabular}

Data are reported as mean \pm SD. Paired Student $t$ test, Intragroup analysis. Vent $=$ Minute Ventilation; ViVol= Inspiratory Tidal Volume; VeVol= Expiratory Tidal Volume; $\mathrm{qDEEL}=$ Change in End-Expiratory Lung Volume Level; $\mathrm{T} i=$ Inspiratory Time; $\mathrm{Te}=$ Expiratory Time; $\mathrm{Tt}=$ Total Breath Time; $\mathrm{Br} / \mathrm{M}=$ Respiratory Rate; $\mathrm{PhRIB}=$ phase relation during inspiration $\mathrm{PhREB}=$ phase relation during expiration; $\mathrm{PhRTB}=$ phase relation of entire breath; $\mathrm{PhAng}=$ phase angle $(\mathrm{PhAng}) ; \mathrm{PifVt}=$ Peak Inspiratory Flow; PifRC $=$ Peak Inspiratory Flow of RC; PifAB= Peak Inspiratory Flow of $\mathrm{AB} ; \mathrm{PiaVt}=$ Peak Inspiratory Acceleration; PiaRC $=$ Peak Inspiratory Acceleration of $\mathrm{RC} ; \mathrm{PiaAB}=$ Peak Inspiratory Acceleration of $\mathrm{AB} ; \% \mathrm{RCi}=$ Percent Rib Cage Inspiratory Contribution to Tidal Volume Ratio. 
Table 3. Anthropometric and spirometric variables of the COPD group classified as Responders $(n=9)$ and Non-Responders ( $n=6)$.

\begin{tabular}{|c|c|c|c|}
\hline Variable & Responder $(n=9)$ & Non-Responder $(n=6)$ & $\mathbf{P}$ \\
\hline Age (years) & $64.7 \pm 8.6$ & $66.2 \pm 5.5$ & 0.71 \\
\hline Gender female & $2 / 22.2$ & $5 / 83.6$ & 0.04 \\
\hline Current smoker & $4 / 44.4$ & $4 / 66.6$ & 0.61 \\
\hline \multicolumn{4}{|l|}{ COPD } \\
\hline Very Severe/Severe/Mild & $1 / 5 / 3$ & $3 / 3 / 0$ & \\
\hline Height (m) & $1.7 \pm 0.1$ & $1.6 \pm 0.1$ & 0.004 \\
\hline Weight (kg) & $66.4 \pm 10.6$ & $66.0 \pm 12.3$ & 0.95 \\
\hline BMI $\left(\mathrm{kg} / \mathrm{m}^{2}\right)$ & $22.7 \pm 2.7$ & $27.4 \pm 6.2$ & 0.06 \\
\hline FVC (\% predicted $)$ & $69.4 \pm 11.6$ & $71.3 \pm 22.7$ & 0.84 \\
\hline $\mathrm{FEV}_{1}(\%$ predicted $)$ & $45.7 \pm 11.5$ & $48.8 \pm 11.4$ & 0.62 \\
\hline $\mathrm{FEV}_{1} / \mathrm{FVC}(\%$ predicted $)$ & $63.6 \pm 10.9$ & $67.2 \pm 4.9$ & 0.47 \\
\hline HR (bpm) & $90.5 \pm 13.2$ & $75.8 \pm 11.5$ & 0.04 \\
\hline $\mathrm{SpO}_{2}(\%)$ & $93.8 \pm 3.2$ & $97.1 \pm 2.0$ & 0.03 \\
\hline $\operatorname{MIP}\left(\mathrm{cmH}_{2} \mathrm{O}\right)$ & $-65.0 \pm 28.0$ & $-64.6 \pm 28.4$ & 0.98 \\
\hline MIP predicted ${ }^{\#}\left(\mathrm{cmH}_{2} \mathrm{O}\right)$ & $-67.5 \pm 13.6$ & $-48.2 \pm 9.6$ & \\
\hline $\operatorname{MEP}\left(\mathrm{cmH}_{2} \mathrm{O}\right)$ & $72.3 \pm 19.3$ & $87.4 \pm 33.0$ & 0.33 \\
\hline MEP predicted ${ }^{\#}\left(\mathrm{cmH}_{2} \mathrm{O}\right)$ & $95.0 \pm 12.0$ & $78.1 \pm 7.8$ & \\
\hline
\end{tabular}

Data are reported as mean \pm SD. Paired Student's t Test, Intergroup analysis. BMI= body mass index; peripheral oxygen saturation $\left(\mathrm{SpO}_{2}\right)$; $\mathrm{FVC}=$ forced vital capacity; $\mathrm{FEV}_{1}=$ forced expiratory volume in first second; $\mathrm{HR}=$ heart rate; $\mathrm{MIP}=$ maximal inspiratory pressure, $\mathrm{MEP}=$ maximal expiratory pressure. \# predicted by Costa et al. ${ }^{15}$.

TEDS significantly increased Vent $(\mathrm{p}=0.001)$, ViVol $(\mathrm{p}=0.002)$, VeVol $(\mathrm{p}=0.001)$, without difference in $\mathrm{Br} / \mathrm{M}(\mathrm{p}=0.226)$. With relation to $\mathrm{qDEEL}$, the delta values were $77.55 \pm 62.82$ for the $\mathrm{R}$ group and $22.41 \pm 45.74$ for the NR. As regards $\mathrm{SpO}_{2}$, during TEDS there was an increase of $3.5 \%$ in the $\mathrm{R}$ group (before: $93.2 \pm 2.5$; during TEDS: $96.5 \pm 3.1 ; \mathrm{p}=0.025$ ) and $1.5 \%$ in the NR group (before: $96.9 \pm 3.2$; during the TEDS: $98.4 \pm 2.6 ; \mathrm{p}=0.011$ ). HR was reduced by $7.0 \%$ in the $\mathrm{R}$ group (before: $81.7 \pm 11.5$; during the TEDS: $76.0 \pm 12.4 ; \mathrm{p}=0.014)$ and $5.1 \%$ in the NR group (before: $68.8 \pm 4.4$; during the TEDS: $65.3 \pm 5.0$; $\mathrm{p}=0.013$ ).

\section{Discussion}

The aim of this study was to evaluate the respiratory pattern during a TEDS session in COPD subjects, and the main results were that the majority of the Responder subjects were men with lower $\mathrm{SpO}_{2}$ and higher HR than the Non-Responders. As regards interaction (time vs. group), this was present in the pulmonary volumes and respiratory frequency, and only the pulmonary volumes were different in the intergroup evaluation. A significant effect of time was also observed on the parameters related to thoracoabdominal synchronism and hyperinflation, in addition to an increase in $\mathrm{SpO}_{2}$ and reduction in HR in the two groups during the TEDS session. These results may have future clinical implications for the usefulness of TEDS in patients with COPD. Regarding peak inspiratory flow and acceleration, higher values were found in the abdominal compartment during the TEDS in the whole COPD group $(n=15)$. When the subjects were divided into the two groups, the difference was only in the interaction (time vs. group) of peak inspiratory flow and \% RCi.

The study by Guerri et al. ${ }^{16}$ demonstrated that "in severe COPD specific respiratory muscle wasting is a predictive variable of susceptibility to and/or the consequence of severe exacerbation and the likelihood of hospitalization for COPD patients" and that "respiratory muscle dysfunction in patients with COPD is not merely a descriptive or anecdotal description". These authors pointed out that "identification of these structural changes in susceptible COPD patients could have important implications for specific strategies such as respiratory muscle training or anabolic treatments". This shows 
Table 4. Plethysmography data of COPD group classified as Responders ( $n=9)$ and Non-Responders $(n=6)$.

\begin{tabular}{|c|c|c|c|c|c|c|c|}
\hline & \multicolumn{2}{|c|}{ Responder Group } & \multicolumn{2}{|c|}{ Non-Responder Group } & \multicolumn{3}{|c|}{$P$-value } \\
\hline & T1 & $\mathbf{T} 2$ & T1 & $\mathbf{T} 2$ & Time & Group & Interaction \\
\hline Vent (L/min) & $6.2 \pm 2.7$ & $8.1 \pm 3.6$ & $9.6 \pm 4.0$ & $7.5 \pm 3.7$ & 0.87 & 0.49 & $0.01 \dagger$ \\
\hline ViVol (mL) & $382.3 \pm 138.9$ & $507.5 \pm 230.3$ & $463.2 \pm 98$ & $388.9 \pm 88.6$ & 0.50 & 0.94 & $0.01 \dagger$ \\
\hline $\mathrm{VeVol}(\mathrm{mL})$ & $388.4 \pm 127.9$ & $507.0 \pm 229.6$ & $451.7 \pm 96.3$ & $390.5 \pm 88.0$ & 0.50 & 0.88 & $0.05 \dagger$ \\
\hline qDEEL & $85.4 \pm 39.1$ & $163.0 \pm 55.6$ & $86.0 \pm 45.7$ & $108.4 \pm 39.0$ & $0.01 *$ & 0.31 & 0.32 \\
\hline $\mathrm{Ti}(\mathrm{s})$ & $1.5 \pm 0.6$ & $1.3 \pm 0.2$ & $1.3 \pm 0.2$ & $1.3 \pm 0.1$ & 0.36 & 0.17 & 0.22 \\
\hline $\mathrm{Te}(\mathrm{s})$ & $2.7 \pm 0.9$ & $2.6 \pm 0.4$ & $2.4 \pm 0.3$ & $2.6 \pm 0.4$ & 0.70 & 0.43 & 0.10 \\
\hline $\mathrm{Tt}(\mathrm{s})$ & $4.2 \pm 1.4$ & $3.9 \pm 0.3$ & $3.6 \pm 0.5$ & $4.0 \pm 0.5$ & 0.63 & 0.24 & 0.11 \\
\hline $\mathrm{Br} / \mathrm{M}(\mathrm{rpm})$ & $16.7 \pm 3.7$ & $17.5 \pm 1.2$ & $17.9 \pm 3.4$ & $16.6 \pm 2.2$ & 0.76 & 0.61 & $0.02 \dagger$ \\
\hline PhRIB (\%) & $12.5 \pm 5.6$ & $19.2 \pm 9.4$ & $11.4 \pm 3.9$ & $20.5 \pm 6.7$ & $0.04 *$ & 0.84 & 0.15 \\
\hline PhREB (\%) & $8.4 \pm 4.0$ & $17.1 \pm 7.4$ & $9.7 \pm 3.3$ & $18.8 \pm 3.9$ & $0.01 *$ & 0.41 & 0.40 \\
\hline PhRTB (\%) & $9.5 \pm 4.2$ & $17.6 \pm 8.9$ & $12.4 \pm 5.0$ & $19.5 \pm 4.4$ & $0.01 *$ & 0.39 & 0.45 \\
\hline PhAng (\%) & $12.6 \pm 7.6$ & $24.3 \pm 9.4$ & $17.1 \pm 7.0$ & $29.7 \pm 11.0$ & $0.002 *$ & 0.20 & 0.84 \\
\hline PifVt & $506.3 \pm 224.9$ & $717.1 \pm 413.2$ & $751.3 \pm 350.9$ & $624.4 \pm 285.1$ & 0.42 & 0.70 & $0.02 \dagger$ \\
\hline PifRC & $329.9 \pm 180.7$ & $414.8 \pm 148.1$ & $416.4 \pm 208.7$ & $352.6 \pm 141.9$ & 0.86 & 0.93 & 0.31 \\
\hline PifAB & $256.4 \pm 136.7$ & $335.3 \pm 207.5$ & $373.8 \pm 230.0$ & $411.5 \pm 226.7$ & 0.06 & 0.25 & 0.79 \\
\hline $\mathrm{PiaVt}$ & $1376.9 \pm 454.7$ & $1806.7 \pm 794.3$ & $1263.7 \pm 334.2$ & $1727.8 \pm 488.7$ & 0.09 & 0.76 & 0.95 \\
\hline PiaRC & $918.2 \pm 338.2$ & $1282.0 \pm 426.8$ & $1021.2 \pm 395.2$ & $1014.3 \pm 357.0$ & 0.06 & 0.42 & 0.27 \\
\hline PiaAB & $609.8 \pm 373.0$ & $796.2 \pm 426.3$ & $859.7 \pm 443.2$ & $948.4 \pm 476.6$ & 0.14 & 0.34 & 0.95 \\
\hline$\% \mathrm{RCi}$ & $65.4 \pm 27.2$ & $74.5 \pm 23.0$ & $53.0 \pm 21.8$ & $52.9 \pm 22.0$ & 0.23 & 0.16 & $0.02 \dagger$ \\
\hline
\end{tabular}

Data are reported as mean $\pm \mathrm{SD}$. T1= Before; $\mathrm{T} 2=$ During the TEDS; two-way ANOVA: *significant time effect $(\mathrm{T} 1 \mathrm{vs.} \mathrm{T} 2)$; $\uparrow$ significant interaction between group and time effects. Vent= Minute Ventilation; ViVol= Inspiratory Tidal Volume; VeVol= Expiratory Tidal Volume; $\mathrm{qDEEL}=$ Change in End-Expiratory Lung Volume Level; $\mathrm{Ti}=$ Inspiratory Time; $\mathrm{Te}=$ Expiratory Time; $\mathrm{Tt}=\mathrm{Total} \mathrm{Breath} \mathrm{Time} ; \mathrm{Br} / \mathrm{M}=$ Respiratory Rate $\mathrm{PhRIB}=$ phase relation in inspiration; $\mathrm{PhREB}=$ phase relation in expiration; $\mathrm{PhRTB}=$ phase relation in total breath; $\mathrm{PhAng}=$ phase angle $(\mathrm{PhAng}) ; \mathrm{PifVt}=$ Peak Inspiratory Flow; PifRC $=$ Peak Inspiratory Flow of RC; PifAB= Peak Inspiratory Flow of $\mathrm{AB} ; \mathrm{PiaVt}=$ Peak Inspiratory Acceleration; PiaRC $=$ Peak Inspiratory Acceleration of $\mathrm{RC} ; \mathrm{PiaAB}=$ Peak Inspiratory Acceleration of $\mathrm{AB} ; \% \mathrm{RC}=\mathrm{Percent}$ Rib Cage Inspiratory Contribution to Tidal Volume Ratio.

that physical therapy treatment has to include respiratory muscle training. With regard to the diaphragm muscle, one specific strategy would be the application of TEDS in order to stimulate fast fibers that are reduced in COPD patients. In this context, there is growing scientific evidence to support strategies that may improve respiratory muscle strength in these patients.

In the present study, it was observed that only a subgroup of patients had an effective response to TEDS, as demonstrated by the increase in pulmonary volume and ventilation values. One variable that can be related to this is the qDEEL, given that this signifies change in end-expiratory lung volume level. But despite the increase in volumes, there was an increase in the contribution of the thorax and abdomen even in non-responsive patients. Therefore, these results indicate that, irrespective of the response, TEDS could promote mobilization of the abdominal and thoracic compartments. It is believed that the application of neuromuscular electrical diaphragm stimulation, which stimulates type IID fibers, may emphasize thoracoabdominal mobility independently from synchronism.

According to Reber et al. ${ }^{17}$, during the normal respiratory cycle, the circumferences of the rib cage and the abdominal wall increase and decrease in synchrony. These movements can be recorded by RIP. The analysis of waveforms can provide quantification of the asynchrony or paradoxical respiratory pattern, in which some measures are used to determine the degree of thoracoabdominal asynchrony, including PhAng, PhRIB, PhREB, and $\mathrm{PhRTB}$. Specifically, PhRIB and PhREB represent the percentage of time during a breath in which the thorax and abdomen walls move in opposite directions and indicate the delay in the thorax wall movement in relation to the abdomen at the beginning 
of inspiration and expiration, respectively. These values range from $0 \%$ (complete synchrony) to $100 \%$ (complete asynchrony) $)^{18}$.

The results of this study showed that the effect of time on the alteration of thoracoabdominal synchronism was significant, irrespective of the group studied; that is, during the intervention with TEDS, there was an increase in thoracoabdominal synchronism. In spite of the values PhRIB, PhREB, and PhRTB being well below $100 \%$, these were shown to increase. This may be related to the new respiratory pattern imposed on the individual, who in spite of being instructed to synchronize voluntary respiration with the respiration generated by the electric current, may have generated this asynchrony. Moreover, in the diaphragm muscle contraction generated by TEDS, the abdominal compartment is displaced inwards, and could thus contribute to the low level of asynchrony generated, irrespective of the group.

Although no reference values were found in COPD in the condition studied, a few studies bring values of these variables in healthy subjects. Parreira et al. ${ }^{19}$ found the following values in healthy subjects aged 60 to 80 years: respiratory rate of $16 \pm 3 \mathrm{rpm}$, Vt of $5.2 \pm 1.8 \mathrm{~L} / \mathrm{min}, \mathrm{PhRIB}$ of $11 \pm 5 \%$, PhREB of $17 \pm 8 \%$, and PhAng of $15 \pm 8^{\circ}$. Although the collection was in the dorsal decubitus position, the population was different and different equipment was used. The study by Panka et al. ${ }^{20}$ also analyzed the breathing patterns of healthy subjects in the same age range as our study (60 years old) but in the seated position, which hinders a comparison. In Alves et al. ${ }^{3}$, the population studied was the same (COPD), but the position of collection was different (sitting on a cycle ergometer) which also makes it difficult to compare the values found in our study. With regard to the $\mathrm{PhAng}$ values being between $0^{\circ}$ for complete synchrony and $180^{\circ}$ for complete asynchrony, some studies have approached $\mathrm{PhAng}$ values in the supine position, which are in the range of $8^{\circ}$ to $9.8^{\circ}$ in healthy subjects $^{21}$ and $14.6^{\circ}$ in COPD subjects ${ }^{22}$. Although the evaluations of the present study were made in another position (semi-Fowler), distinct values were observed in the groups, being 12.6 \pm 7.6 in R group and 17.1 \pm 7.0 in NR group. During the TEDS session, this variable as well as the other thoracoabdominal coordination variables were also shown to increase in the groups. In the same way, $\mathrm{SpO}_{2}$ improved similarly in both groups, regardless of the responses in tidal volume. These results are important because electrical stimulation of the diaphragm may improve oxygenation independently from improvement in tidal volume or ventilation. The possible explanation for these results may be inferred from the fact that TEDs may have reduced the hyperinflation of these patients, however direct analysis of lung static volumes was not performed in this study and will need to be evaluated in future studies.

Although some studies in the literature have shown positive results related to TEDS treatment ${ }^{7-9,23-25}$, no studies related to respiratory pattern behavior in COPD patients during TEDS sessions were found. As this aspect could be important to obtaining a better understanding of the results after a long treatment with this resource, we suggest that future studies evaluate the respiratory pattern of COPD subjects who underwent pulmonary rehabilitation combined with TEDS to allow the assessment of the synchronism variables and pulmonary volume behavior after the associated treatment. This is important because the resource could be beneficial to the diaphragm muscle as regards muscle strength, thoracoabdominal mobility, and respiratory pattern.

With regard to time variables, the respiratory times found in the plethysmographic analysis were similar to the standard set in Phrenics ${ }^{\circledR}$, the specific equipment for the TEDS application. The standardized times in the electrical current were 1.1 seconds of contraction (inspiration) and 2.9 seconds of relaxation (expiration), with a total of 3.9 seconds. In the plethysmographic analysis, the values were similar in both groups. This shows that the subjects maintained the parameters specified in the electrical current during TEDS. With relation to $\mathrm{Br} / \mathrm{M}$ during TEDS, the small difference compared to the value of $15 \mathrm{rpm}$ inserted in equipment can be explained by spontaneous breaths performed between breaths stimulated by TEDS, however it was non-significant.

As for derivative and acceleration measures, there was a difference in the whole COPD group $(n=15)$, in which the TEDS promoted increase in PifAB and PiaAB, showing that this resource had a greater effect on the abdominal compartment. This fact can be related to its action on the abdomen by contracting the diaphragm muscle. However, in the R and NR groups, the difference was only in the interaction (group vs. time), specifically in PifVt and \% RCi, without difference in between-group and betweentime analysis.

The main limitation of the present study was the impossibility of controlling static lung volumes and other respiratory work parameters. Thus, the inferences of this study were speculative. In addition, these results are short-term and restricted to patients with stable COPD, not necessarily with respiratory muscle weakness. Therefore, analysis of the effects on this specific population are necessary 
in future studies. Finally, the electrical diaphragmatic stimulation used in the present study is a noninvasive method, which may also partially stimulate the intercostal muscles and diaphragm fibers. However, this approach has been studied in humans because, unlike phrenic stimulation, it is more tolerable, does not cause pain, and does not pose a risk to patients ${ }^{12}$.

Therefore, in view of the results of this study, we conclude that TEDS was beneficial in increasing the pulmonary volumes in a subgroup of COPD patients with greater hypoxemia and HR; however, irrespective of the increase in pulmonary volumes, TEDS increased $\mathrm{SpO}_{2}$ and reduced HR. These results may have clinical relevance for the use of TEDS in patients with COPD. Nevertheless, future studies must be conducted with TEDS in patients with COPD with respiratory muscle weakness in order to evaluate the long-term effects of TEDS.

\section{Acknowledgements}

Quark $^{\circledR}$ Medical Products. Financial support: PNPD (Programa Nacional de Pós-Doutorado) and Conselho Nacional de Desenvolvimento Científico e Tecnológico (CNPQ), Brazil (Process number 151755/2008-6 / Project 559018/2008-8); Fundação de Amparo a Pesquisa do Estado de São Paulo (FAPESP), Brazil (Process number 05/59427-7) and volunteers.

\section{References}

1. Weiner P, McConnell A. Respiratory muscle training in chronic obstructive pulmonary disease: inspiratory, expiratory, or both? Curr Opin Pulm Med. 2005;11(2):140-4. http://dx.doi.org/10.1097/01. mcp.0000152999.18959.8a

2. McKenzie DK, Butler JE, Gandevia SC. Respiratory muscle function and activation in chronic obstructive pulmonary disease. J Appl Physiol. 2009;107(2):6219. PMid:19390004. http://dx.doi.org/10.1152/ japplphysiol.00163.2009

3. Alves GS, Britto RR, Campos FC, Vilaça AB, Moraes KS, Parreira VF. Breathing pattern and thoracoabdominal motion during exercise in chronic obstructive pulmonary disease. Braz J Med Biol Res. 2008;41(11):945-50. http:// dx.doi.org/10.1590/S0100-879X2008001100001

4. Nici L, Donner C, Wouters E, Zuwallack R, Ambrosino $\mathrm{N}$, Bourbeau J, et al. American Thoracic Society/European Respiratory Society statement on pulmonary rehabilitation. Am J Resp Crit Care Med. 2006;173(12):13901413. PMid:16760357. http://dx.doi.org/10.1164/ rccm.200508-1211ST

5. Laviolette L, Bourbeau J, Bernard S, Lacasse Y, Pepin $\mathrm{V}$, Breton MJ, et al. Assessing the impact of pulmonary rehabilitation on functional status in COPD. Thorax.
2008;63(2):115-21. PMid:17901158. http://dx.doi. org/10.1136/thx.2006.076844

6. Wijkstra PJ, Wempe JB. New tools in pulmonary rehabilitation. Eur Respir J. 2011;38(6):146874. PMid:21828026. http://dx.doi. org/10.1183/09031936.00111911

7. Sarnoff SJ, Maloney JV, Sarnoff LC, Ferris BG Jr, Whittenberger JL. Electrophrenic respiration in acute bulbar poliomyelitis; its use in management of respiratory irregularities. J Am Med Assoc. 1950;143(16):1383-90. http://dx.doi.org/10.1001/jama.1950.02910510001001

8. Sarnoff SJ, Sarnoff LC, Wittenberger JL. Electrophrenic respiration. The motor point of the phrenic nerve in relation to external stimulation. Surg Gynecol Obstet. 1951;93(2):190-6. PMid:14855265.

9. Goldenthal S. Bilateral and unilateral activation of the diaphragm in the intact human. External electrical stimulation by capacitive coupling as recorded by cineradiography. Conn Med. 1961;25:236-8. PMid:13706500.

10. Rabe KF, Hurd S, Anzueto A, Barnes PJ, Buist SA, Calverley P, et al. Global strategy for the diagnosis, management, and prevention of chronic obstructive pulmonary disease: GOLD executive summary. Am J Resp Crit Care Med. 2007;176(6):532-55. PMid:17507545. http://dx.doi.org/10.1164/rccm.200703-456SO

11. Cancelliero KM, Ike D, Sampaio LMM, Santos VLA, Stirbulov R, Costa D. Transcutaneous electrical diaphragmatic stimulation (TEDS) for the respiratory muscle strengthening: randomized and controlled clinical study. Phys Ther Res. 2012;19(4):303-8.

12. Geddes LA, Voorhees WD, Lagler R, Riscili C, Foster K, Bourland JD. Electrically produced artificial ventilation. Med Instrum. 1988;22(5):263-71. PMid:3054441.

13. Chadha ST, Watson H, Birch S, Jenouri GA, Schneider AW, Cohn MA, et al. Validation of respiratory inductive plethysmography using different calibration procedures. Am Rev Respir Dis. 1982;125:644-9. PMid:7091869.

14. Vivologic Operator's Manual. Ventura: VivoMetrics, Inc.; 2005.

15. Costa D, Gonçalves HA, Lima LP, Ike D, Cancelliero KM, Montebelo MI. New reference values for maximal respiratory pressures in the Brazilian population. J Bras Pneumol. 2010;36(3):306-12. PMid:20625667. http:// dx.doi.org/10.1590/S1806-37132010000300007

16. Guerri R, Gayete A, Balcells E, Ramirez-Sarmiento A, Vollmer I, Garcia-Aymerich J, et al. Mass of intercostal muscles associates with risk of multiple exacerbations in COPD. Respir Med. 2010;104(3):378-88. PMid:19932014. http://dx.doi.org/10.1016/j.rmed.2009.10.015

17. Reber A, Geiduschek JM, Bobbià SA, Bruppacher HR, Frei FJ. Effect of continuous positive airway pressure on the measurement of thoracoabdominal asynchrony and minute ventilation in children anesthetized with sevoflurane and nitrous oxide. Chest. 2002;122(2):473-8. http://dx.doi.org/10.1378/chest.122.2.473

18. Rusconi F, Gagliardi L, Aston H, Silverman M. Respiratory inductive plethysmography in the evaluation of lower airway obstruction during methacholine challenge 
in infants. Pediatr Pulmonol. 1995;20(6):396-402. http:// dx.doi.org/10.1002/ppul.1950200610

19. Parreira VF, Bueno CJ, França DC, Vieira DSR, Pereira DR, Britto RR. Breathing pattern and thoracoabdominal motion in healthy individuals: influence of age and sex. Rev Bras Fisioter. 2010;14(5):411-6. http://dx.doi. org/10.1590/S1413-35552010000500010

20. Panka GFL, Oliveira MM, França DC, Parreira VF, Britto RR, Velloso M. Ventilatory and muscular assessment in healthy subjects during an activity of daily living with unsupported arm elevation. Rev Bras Fisioter. 2010;14(4):337-43. http://dx.doi.org/10.1590/ S1413-35552010005000013

21. Block KE, Barandun J, Sackner MA. Effect of mouthpiece breathing on cardiorespiratory response to intense exercise. Am J Resp Crit Care Med. 1995;151(4):1087-92.

22. Sackner MA, Gonzalez H, Rodriguez M, Belsito A, Sackner DR, Grenvik S. Assessment of asynchronous and paradoxic motion between rib cage and abdomen in normal subjects and in patients with chronic obstructive pulmonary disease. Am Rev Respir Dis. 1984;130(4):58893. PMid:6486558.

23. Costa D, Forti EMP, Barbalho-Moulim MC, Rasera I Jr. Study on pulmonary volumes and thoracoabdominal mobility in morbidly obese women undergoing bariatric surgery, treated with two different physical therapy methods. Rev Bras Fisioter. 2009;13(4):294-301. http:// dx.doi.org/10.1590/S1413-35552009005000041

24. Forti EMP, Ike D, Barbalho-Moulim MC, Rasera I Jr, Costa D. Effects of chest physioterapy on the respiratory funcion of postoperative gastroplasty patients. Clinics. 2009;64(7):683-9. PMid:19606246 PMCid:PMC2710443. http://dx.doi.org/10.1590/S1807-59322009000700013

25. Criner GJ, Travaline JM, Holt GA, Bosse CG, Kelsen SG. Variability of electrophrenic diaphragm twitch stimulation over time in normal subjects. Resp Physiol. 1999;118(1):3947. http://dx.doi.org/10.1016/S0034-5687(99)00057-2

\section{Correspondence}

\section{Dirceu Costa}

Universidade Nove de Julho (UNINOVE)

Programa de Pós-Graduação em Ciências da Reabilitação Rua Vergueiro, 235, Liberdade

CEP 01504-001, São Paulo, SP, Brasil

e-mail: dcosta@uninove.br; dirceu@ufscar.br 